\title{
Isolation and characterization of bacterial isolates for biological control of clubroot on Chinese cabbage
}

\author{
Lihong Zhou • Lihui Zhang • Yueqiu He • Feng Liu • \\ Miao Li • Zhengshuo Wang • Guanghai Ji
}

Accepted: 5 May 2014 / Published online: 14 May 2014

(C) The Author(s) 2014. This article is published with open access at Springerlink.com

\begin{abstract}
Clubroot caused by Plasmodiophora brassicae is becoming an emerging threat to the production of crucifer vegetable crops in China. The aim of this study was to develop an effective biocontrol strategy against clubroot of Chinese cabbage. Results indicated that six out of fourteen bacterial strains that were isolated from vegetable rhizosphere soil reduced disease severity of Chinese cabbage by more than $50 . \%$ under greenhouse conditions.In greenhouse experiments, a soil-drench application of strain YFY 02, 13-1 and HY cell-free culture filtrate reduced the clubroot by $37.7-$ $74.6 \%$ relative to pathogen post-inoculation control on the highly susceptible Chinese cabbage cultivar. Seed treatment of strain YFY 02, 13-1 and HY cell-free culture filtrate reduced clubroot by $23.8-56.0 \%$ in greenhouse experiments. In two field trials conducted at Tonghai and Lufeng sites, cell-free culture filtrates of three isolates reduced clubroot severity on Chinese cabbage by $62.4-76.8 \%$ and $79.4 \%-85.1 \%$, respectively. This efficacy was similar to fungicide Cyazofamid. Based on the sequence analysis of the 16S rDNA gene and identification of biochemical and physiologica criteria 1(Biolog carbon source utilization analysis), the strains YFY 02 and HY were identified as Lysobacter antibioticus. To our knowledge, this is the first report of L. antibioticus strains being a promising candidate as a biological control agent against clubroot.
\end{abstract}

L. Zhou $\cdot$ L. Zhang $\cdot$ Y. He $\cdot$ F. Liu $\cdot$ M. Li $\cdot$ Z. Wang $\cdot$ G. Ji $(\bowtie)$

Key Laboratory of Agricultural Biodiversity for Plant Disease Management under the Ministry of Education, Yunnan Agricultural University, Kunming 650201, PR China e-mail: jghai001@aliyun.com
Keywords Plasmodiophora brassicae - Lysobacter antibioticus · Antagonistic bacteria $\cdot 16 \mathrm{~S}$ rDNA Soil drench

\section{Introduction}

Clubroot, caused by the obligate parasite Plasmodiophora brassicae, is an economically important disease affecting plants in the family Brassicaceae worldwide (Howard et al. 2010; Dixon 1998). In China, the disease has raised concerns because of the rapid increase in the number of clubroot-infested fields in recent years. Nowadays, the disease has become the main limiting factor for the production of cruciferous crops in almost all provinces, in particular, Liaoning, Zhejiang, Jiangxi, Sichuan and Yunnan provinces (Huang 2010; Wang et al. 2011). This may be due toChinese cabbage being one of the major crops in these provinces, one-third of which is traditionally planted in acidic soils that favour disease development (Howard et al. 2010). In a study from Yunnan province, it was found that losses were as high as $81 \%$ when Chinese cabbage was planted in P. brassicae-infested soils (Feng et al. 2013). Crop rotation is the simplest and most effective approach for the management of clubroot, but may not be practical due to the longevity of the pathogen in infested soils (Haiyan, Xu 2011).

Application of lime suppresses disease development, but is not economically feasible because large quantities of lime and repeated applications are required (Donald et al. 2002). Despite the variable effect of fungicides such as carbendazol, chlorothalonil, fluazinam, cyazofamid, the application of calcium 
cyanamide has been considered as an effective management option, although at an expensive cost (Suzuki et al. 1995; Takeshi et al. 2004). A resistant cultivar of Chinese cabbage could be a better choice. However, to-date, no clubroot-resistant cultivars of Chinese cabbage are available in Yunnan province, although the development of resistant cultivars is a desirable alternative approach for controlling this disease (Yong et al. 2009). Fortunately, biological control has been found to be an ecologically-based, cost effective, and sustainable alternative method for clubroot management(Jaschke et al. 2010).

Several studies have illustrated the biocontrol potential of antagonistic microbes in reducing both incidence and severity of clubroot (Cheah et al. 2000; Joo et al. 2004; Wang et al. 2011). Indeed, Narisawa (1998) reported the endophytic fungus Heteroconium chaetospira could be used as a potential biocontrol agent for the management of clubroot in Chinese cabbage in both greenhouse and field tests. Furthermore, three isolates of endophytic actinomycetes effectively suppressed the occurrence of Chinese cabbage clubroot in pots, while the control efficiency was $42 \%$ for strain A018 of Streptomyces olivochromogenes, $58 \%$ and $33 \%$ for strain A 004 and A 011 of Microbispora rosea subsp. rosea, respectively (Lee et al. 2008). In addition, Bacillus subtilis isolate XF-1 from Chinese cabbage rhizosphere soil effectively suppressed the occurrence of Chinese cabbage clubroot by 68.6-84.8 \% (Yueqiu et al. 2008). Various mechanisms have been proposed for microbial antagonists, such as production of antimicrobial metabolites (Arie et al. 1999; Kim et al. 2004), or colonization of plant roots (Usuki and Narisawa 2007), or resistant induction in the host (Morita et al. 2003). In general, biocontrol of clubroot is attractive because soil microbes are able to colonize host roots or the rhizosphere, thus providing durable protection.

The genus Lysobacter, described by Christensen and Cook (1978), consists of 16 species with validly published names such as L. antibioticus, L. brunescens, L. enzymogenes and L. gummosus (Sullivan et al. 2003; Islam et al. 2005; Romanenko et al. 2008). Furthermore, previous studies have revealed the biocontrol potential of some Lysobacter strains (Zhang and Yuen 1999; Folman et al. 2003). Indeed, L. enzymogenes strain $\mathrm{C} 3$ has been used as a natural antagonist of Rhizoctonia solani and Bipolaris sorokiniana on turf grass (Yuen and Zhang 2001),
L. enzymogenes strain 3.1 T8 efficiently reduced Pythium aphanidermatum infection of cucumber (Folman et al. 2004), Lysobacter sp. strain SB-K88 was antagonistic to a large number of oomycetes, by producing xanthobaccins (Islam et al. 2005), and Lysobacter capsici strain PG 4 isolated from the rhizosphere of a tobacco plant drastically reduced the incidence of tomato crown and root rot and caused a marked increase in plant fresh weight (Puopolo et al. 2010). However, at the time of writing, no reports on controlling clubroot disease by Lysobacter spp. have been documented.

The objectives of this study were to: (i) isolate Lysobacter spp. from roots of Chinese cabbage and then assess their in vivo suppressive effects against clubroot caused by $P$. brassicae; (ii) identify the selected strains with biocontrol potential by morphological and cultural traits, physio-biochemical characteristics as well as $16 \mathrm{~S}$ ribosomal DNA (rDNA) sequence and phylogenetic analyses; and (iii) evaluate the biocontrol efficiency of the selected strains against clubroot under both greenhouse and field conditions.

\section{Materials and methods}

\section{Bacterial isolation and identification}

Rhizosphere soil of Chinese cabbage (Brassica campestris L.) and other vegetables were collected from different locations in Yunnan province(Yang et al. 2009), in 2010 and 2011. Bacteria were isolated by suspending $1 \mathrm{~g}$ of soil samples into sterile water and serially diluted in sterile water up to $10^{-7} \mathrm{CFU} / \mathrm{ml}$ (Zhongda 1998). An aliquot of $0.1 \mathrm{ml}$ of the dilution was plated on nutrient agar (NA). After 3 days of incubation at $28{ }^{\circ} \mathrm{C}$, the obtained bacterial colonies were purified on NA plate three times and stored in $30 \%$ glycerol at $-80{ }^{\circ} \mathrm{C}$.

All isolates were used in the test of biocontrol efficacy against clubroot on Chinese cabbage under greenhouse condition. To select effective biocontrol agents against Chinese cabbage clubroot, the bacterial isolates were used as a soil-drench in a greenhouse experiments. Highly susceptible seeds of Chinese cabbage (cv. 83-1) were sown in a soilless mix in plastic pots (10 cm diameter, $20 \mathrm{~cm}$ depth). Only the strains which could restrain the clubroot pathogen were used in further study. 
The bacterial isolates with biocontrol potential were identified based on the analysis of 16S rDNA sequences. Genomic DNA of each isolate was extracted with a Qiagen Genomic DNA Kit. The 16S rDNA was amplified using the universal primers $27 \mathrm{~F}$ (5"-AGAGTTTG ATCCTGGCTCAG-3"') and 1492 R (5'-GGTTACCT TGTTACGACTT-3'). Each PCR reaction was carried out in a final volume of $25 \mu \mathrm{L}$, containing 5-10 ng genomic DNA, $2.5 \mathrm{mM} \mathrm{MgCl}, 40 \mathrm{nM}$ PCR primers, $2 \mathrm{mM}$ dNTP MIX and $0.5 \mathrm{U}$ of Taq DNA polymerase (TaKaRa). The sample was subjected to the following temperature cycling profile: $94^{\circ} \mathrm{C}$ for $5 \mathrm{~min}$; followed by 35 cycles of $94{ }^{\circ} \mathrm{C}$ for $30 \mathrm{sec}, 50^{\circ} \mathrm{C}$ for $30 \mathrm{sec}, 72{ }^{\circ} \mathrm{C}$ for $1.5 \mathrm{~min}$; with a final extension step of $10 \mathrm{~min}$ at $72{ }^{\circ} \mathrm{C}$. The PCR products were purified using a Uniq EZ Spin Column DNA Gel Extraction Kit (Shanghai, China) and then sequenced on an ABI prism 377-96 DNA sequencer with $9 \mathrm{~F}$ and $1541 \mathrm{R}$ primers. The determined $16 \mathrm{~S}$ rDNA sequences were compared with the Genbank databases by using the BLAST search program. Phylogenetic tree were constructed based on software Primer primer 5 and the BLAST results from NCBI with the $16 \mathrm{~S}$ rDNA sequence of the bacterial isolates. For phylogenetic analyses, 16S rDNA sequences of isolates YFY 02, HY, and 13-1 were aligned with reference sequences obtained from the nucleotide sequence database in NCBI by using CLUSTALW. A phylogenetic tree was constructed with the MEGA 5.0 software package by using a neighbor-joining method.

Three bacteria were also identified based on the biochemical and physiological identification by Biolog carbon source utilization analysis (Lihong and Guanghai 2013). The strain identification test used the Biolog microstation TM V4.01 system; the gramnegative bacteria microplate and database were chosen to identify these strains.

Antagonists and pathogen cultures

Bacterial isolates were inoculated into nutrient broth and incubated at $28^{\circ} \mathrm{C}$ for three days with constant shaking at $180 \mathrm{rpm}$. The cell concentration was adjusted to $3 \times$ $10^{8} \mathrm{CFU} / \mathrm{ml}\left(0.1 \mathrm{OD}\right.$ at $595 \mathrm{~nm}=10^{8} \mathrm{CFU} / \mathrm{ml}$ )(Webster and Dixon 1991b), while the whole-broth culture (WBC) of bacterial isolates was used as the standard treatment. The biocontrol effects of various culture components were also examined by separating the WBC into cellular and supernatant fractions. The supernatant obtained by centrifuging bacterial suspensions at
$12,000 \mathrm{rpm}$ for $5 \mathrm{~min}$ was further filtered through a $0.22 \mu \mathrm{m}$ filter, while the filtrate was designated as cellfree culture fluid (CFC).

Clubroot galls were collected from infested Chinese cabbages in Kunming, Yunnan province, China, where the pathogen populationss are dominated by pathotype 4 , identified using Williams' differential varieties (Feng et al. 2013). Galls were air dried and stored at $-20{ }^{\circ} \mathrm{C}$ until required. To extract resting spores, about $3 \mathrm{~g}$ of dried galls were soaked in $150 \mathrm{ml}$ distilled water for $2 \mathrm{~h}$ to soften the tissue and then macerated in a blender at high speed for $2 \mathrm{~min}$. The resulting slurries were filtered through four layers of nylon cloth and the concentration of spores was estimated using a haemocytometer. A spore density of $4 \times 10^{7} / \mathrm{ml}$ was used for inoculation.

\section{Greenhouse experiments}

To select effective biocontrol agents against Chinese cabbage clubroot in vivo, the bacterial isolates were used as a soil-drench or seed treatment in separate experiments in a greenhouse. Highly susceptible seeds of Chinese cabbage (cv. 83-1) were sown in a soilless mix in plastic pots (10 $\mathrm{cm}$ diameter, $20 \mathrm{~cm}$ depth). The soilless mix consisted of grass carbon, and a little soil mix (pH 5.8-6.2) amended with $1 \%(\mathrm{~W} / \mathrm{V})$ composite fertilizer.

For bacterial soil-drench applicaAH tion, each pot (Chinese cabbage cv. 83-1) was inoculated with $50 \mathrm{ml}$ of different bacterial CFC described as above. The pathogen was inoculated with $4 \times 10^{7}$ resting spores of pathogen per pot. The phenazino-1-carboxylic(Peng et al. 2009, 2010) acid was inoculated with 4-7 ug per pot. The application time of antagonistic bacteria was as follows. (i) The bacterial isolates were applied prior to the pathogen inoculum to allow earlier establishment of bacterial isolates. (ii) The bacterial isolates and pathogen inoculum were applied at the same time after 3 days of seeding. (iii) Growth substrates were generally infested with the pathogen before the application of bacterial isolates so as to better mimic infestation of field soils.

For bacterial seed-treatment application, seeds of Chinese cabbage cv. 83-1 were immersed in different types of CFC described as above for 1 day in the dark after washing three times with sterile water to remove surface-coated microbicides. Seed were then air dried for $1 \mathrm{~h}$ prior to sowing and then all treatments were applied 3 days after seeding as described earlier. The 
phenazino-1-carboxylic acid was applied at 4-7 ug per pot. The application time of antagonistic bacteria was as described above.

All plants were watered with sterile water ( $\mathrm{pH} 6.3$ ), and the soil in each pot was kept moist by daily watering. For each of the greenhouse trials, the study was laid out in a randomized complete block design with four replicates and 10 plants per replicate. Only three highly reproducible replicates were used in data analysis. Each greenhouse trial was repeated. After maintaining the plants in a greenhouse for 6-8 weeks, roots were collected and rinsed with tap water and then assessed for clubroot incidence and severity. Clubroot disease severity was calculated by the percentage of infected plants.

\section{Field Experiments}

During 2011 to 2012, the biocontrol efficiency of four products against clubroot of Chinese cabbage was further assessed in three commercial fields with a heavy infection of clubroot at two counties near Kunming, Yunnan, where pathotype 4 of $P$. brassicae predominated (Feng et al. 2013). The trials were arranged in a randomized complete block design with four replicates. Only three highly reproducible replicates were used in data analysis. Each plot consisted of four $6 \mathrm{~m}$-long rows with a row spacing of $50 \mathrm{~cm}$ for Chinese cabbage. The susceptible cv. Chunxibawang No.1 and Chenzha No.5 of Chinese cabbage were purchased from Kunming Seeds Inc. Biocontrol agents and fungicide (cyazofamid, 60-100 g/hm²) (Peng et al. 2009, 2010) was applied twice as a soil drench at 7 and 14 days after sowing, respectively, while each seed furrow was inoculated with $100 \mathrm{ml}$ of different bacterial CFC described as above or $1 \%$ phenazino-1-carboxylic acid at $0.75 \mathrm{~kg} / \mathrm{Ha}$. The control was inoculated with water. At 8 weeks after sowing, clubroot severity was determined by digging about 200 Chinese cabbages from the central area of each plot and rating each plant as described above.

\section{Data Analysis}

The categories of diseased or not diseased were used to rate the plants and the percentage of diseased plants was used to calculated disease severity. Analysis of variance for clubroot disease severity of plants was performed using the generalised linear mode $1(\mathrm{GLM})$ procedure.
Mean comparisons were conducted using a least significant difference (LSD) test $(P=0.05$ or $P=0.01)$. Standard error and LSD results were recorded. All the variables were categorical variables. The distribution was conformed with a binomial error distribution. .

\section{Results}

In vivo biocontrol activity against Chinese cabbage clubroot

Although the total numbers of bacterial strains was 46, only 17 strains could restrain the clubroot pathogen, and were used in this study. Among the 17 bacterial isolates tested, six isolates gave a greater than $50.0 \%$ reduction in clubroot severity, while the other bacterial isolates had little or no effect (Table 1). Indeed, the six isolates YFY 02, HY, 13-1, B 908, B 3 and M 4 reduced clubroot severity by $73.2 \%, 52.4 \%, 68.0 \%, 52.0 \%$, $58.8 \%$ and $54.4 \%$ compared to the CK, respectively. This indicated that the six isolates were effective in controlling Chinese cabbage clubroot under greenhouse conditions. Isolates B 908, B 3 and M 4 were Bacillus species which have been reported for clubroot control (Kinsella et al. 2009); hence the three Lysobacter isolates were selected as potential biocontrol agents for further studies

\section{Identification of antagonistic isolates}

The bacterial strains YFY 02, HY, 13-1 isolated in the present study were identified as $L$. antibioticus based on biochemical and physiological identification (Biolog carbon source utilization analysis) and $16 \mathrm{~S}$ rDNA sequences analysis.

The biochemical and physiological identification showed a similar carbon source utilization of three strains. The strain HY could utilize 88 kinds of carbon source except Tween 80(A6), D-Galactonic Acid Lactone(D5), p-Hydroxy Phenylacetic Acid(E1), Sebacic Acid(E11), D-Serine(G8), $\gamma$-Amino Butyric Acid(G12), Phenyethylamine(H5). There were five carbon source strain which YFY 02 could not utilize, while HY could utilize them. These carbon source were D-cellobiose(A12), D-Fructose(B2), DMannose(B12), Succinic Acid(E12), L-Histidine(G1) . There were only three kinds of carbon showing different source utilization for strains 13-1 and YFY 02: 
Table 1 Biocontrol efficiency of 17 isolates against clubroot on Chinese cabbage under greenhouse condition ${ }^{\mathrm{a}}$.

\begin{tabular}{lll}
\hline Treatment & Habitat & Disease severity (\%) \\
\hline CK & - & $68 \mathrm{a}$ \\
YFY 02 & Rhizosphere & $62 \mathrm{~b}^{\mathrm{b}}$ \\
HY & Rhizosphere & $65 \mathrm{a}$ \\
$13-1$ & Rhizosphere & $60 \mathrm{~b}$ \\
$13-3$ & Rhizosphere & $45 \mathrm{~d}$ \\
$13-4$ & Rhizosphere & $42 \mathrm{~d}$ \\
$13-5$ & Rhizosphere & $48 \mathrm{c}$ \\
$13-2$ & Rhizosphere & $43 \mathrm{~d}$ \\
$13-7$ & Rhizosphere & $50 \mathrm{c}$ \\
B908 & Soil & $54 \mathrm{c}$ \\
B3 & Soil & $53 \mathrm{c}$ \\
M4 & Interior of stem & $54 \mathrm{c}$ \\
BG & Chinese cabbage rhizosphere & $57 \mathrm{~b}$ \\
1 h1 & Endosphere & $54 \mathrm{c}$ \\
IV1 & Endosphere & $24 \mathrm{e}$ \\
M1 & Endosphere & $26 \mathrm{e}$ \\
M2 & Endosphere & $28 \mathrm{e}$ \\
M3 & Interior of stem & $21 \mathrm{f}$ \\
$\mathrm{R}^{\mathrm{c}}$ & - & $55 \mathrm{c}$ \\
\hline
\end{tabular}

a. Plants were inoculated with $50 \mathrm{ml}$ of different bacterial CFC described as above while the CK was treated with sterile water of the same volume. The resting spore of Plasmodiophora brassicae was inoculated by soil-drenching in all treatments as described.

b.Means followed by the same letter within a column are not significantly different as determined by the LSD test $(p=0.05)$. The data were expressed as the average of three replications and three repetitions.

c.The "R" means " phenazino-1-carboxylic acid".

Acetic Acid(D1), $\beta$-Hydroxy(D11), Butyric Acid LOrnithine(G4) (Table 2).

A unique PCR product of approximately $1451 \mathrm{bp}$ was generated for the three antagonistic bacteria. The partial 16S rDNA sequence of the isolates YFY 02, HY and 13-1 were determined and deposited in NCBI database under the accession numbers of EF 139190, HQ 693084 and DQ 188260, respectively. BLAST analyses showed that the partial 16S rDNA sequence of the isolates YFY 02, HY and 13-1 had greater than $98 \%$ similarity to those of other L. antibioticus strains that had been deposited in the GenBank database. In addition, the phylogenetic analysis revealed that the three isolates YFY 02, HY, and 13-1 and other L. antibioticus strains clustered within a group and well separated from other species of Lysobacter (Fig. 1).

\section{Biocontrol efficiency under greenhouse conditions}

Chinese cabbages inoculated with the pathogen alone caused $70.0 \%, 74.2 \%$ and $58.9 \%$ disease severities in trials 1,2 and 3 , respectively; while clubroot severity was reduced by both the bacterial isolates and fungicide used as a soil drench. When applied prior to the pathogen inoculation in trial 1, the three isolates YFY 02, HY, and $13-1$ and fungicide caused a $28.0 \%, 17.8 \%, 30.0 \%$ and $34.0 \%$ disease severity, respectively. When applied at the same time with pathogen inoculation in trial 2, the three isolates YFY 02, HY, and 13-1 and fungicide caused a $34.7 \%, 34.7 \%, 42.0 \%$ and $58.7 \%$ disease severity, respectively. When applied after the pathogen inoculation in trial 3, the three isolates YFY $02, \mathrm{HY}$, and $13-1$ and fungicide caused a $20.0 \%, 34.5 \%, 36.7 \%$ and $38.0 \%$ disease severity, respectively. (Table 3 ).

Most treatments of trial 1 and trial 2 showed a better clubroot suppression effect than trial 3 except YFY 02, so we chose the inoculation times of trial 1 and trial 2 in seed treatments. The three bacterial isolates and fungicide (phenazino-1-carboxylic acid) and chitosan used as a seed treatment also reduced clubroot severity. When applied prior to the pathogen inoculation in trial 1, the three isolates YFY 02, HY, 13-1 and fungicide as well as chitosan caused a $61.9 \%, 66.7 \%, 54.7 \%, 52.6 \%$ and $72.6 \%$ disease severity, respectively.. When applied at the same time with pathogen inoculation in trial 2, the three isolates YFY 02, HY, 13-1 and fungicide as well as chitosan caused a $68.1 \%, 62.6 \%, 54.3 \%$, $65.0 \%$ and $69.0 \%$ disease severity, respectively (Table 4). Chinese cabbage inoculated with the pathogen alone caused a $100.0 \%$ and $93.0 \%$ disease severity in trial 1 and trail 2.

\section{Field experiments}

In field experiments, clubroot severity on Chinese cabbage was $70.0 \%$ and $43.6 \%$, respectively, in Tonghai and Lufeng. However, in Tonghai, Chinese cabbage plants treated with YFY 02, HY, 13-1 and fungicide $1 \%$ phenazino-1-carboxylic acid and cyazofamid caused a $26.0 \%, 34.0 \%, 45.0 \%, 64.0 \%$ and $33.0 \%$ reduction in disease severity compared to the pathogen, while in Lufeng Chinese cabbage plants treated with YFY 02, HY, 13-1 and fungicide $1 \%$ phenazino-1carboxylic acid and cyazofamid caused a $23.1 \%$, $20.5 \%, 23.0 \%, 26.0 \%$ and $5.5 \%$ reduction in disease severity compared to the control (Table 5). 
Table 2 Biochemical and physiological identification of HY

\begin{tabular}{|c|c|c|c|c|c|c|c|c|}
\hline No. & Nutrient & reaction & No. & Nutrient & reaction & No. & Nutrient & reaction \\
\hline A1 & water & & C9 & Turanose & + & F5 & D-Alanine & + \\
\hline $\mathrm{A} 2$ & a-Cyclodextrin & $+{ }^{\mathrm{a}}$ & $\mathrm{C} 10$ & Xylitol & + & F6 & L-Alanine & + \\
\hline A3 & Dextrin & + & $\mathrm{C} 11$ & Methyl Pyruvate & + & F7 & L-Alanyl-glycine & + \\
\hline A4 & Glycogen & + & $\mathrm{C} 12$ & Mono-Methyl-Succinate & + & F8 & L-Asparagine & + \\
\hline A5 & Tween 40 & + & D1 & Acetic Acid & + & F9 & L-Aspartic Acid & + \\
\hline A6 & Tween 80 & - & D2 & Cis-Aconitic Acid & + & F10 & L-Glutamic Acid & + \\
\hline A7 & N-Acetyl-D-Galactosamine & + & D3 & Citric Acid & + & F11 & Glycyl-L-Aspartic Acid & + \\
\hline A8 & N-Acetyl-D-Glucosamine & + & D4 & Formic Acid & + & $\mathrm{F} 12$ & Glycyl-L-Glutamic Acid & + \\
\hline A9 & Adonitol & + & D5 & D-Galactonic Acid Lactone & - & G1 & L-Histidine & + \\
\hline A10 & L-Arabinose & + & D6 & D-Galacturonic Acid & + & G2 & Hydroxy-L-Proline & + \\
\hline A11 & D-Arabitol & + & D7 & D-Gluconic Acid & + & G3 & L-Leucine & + \\
\hline A12 & D-cellobiose & + & D8 & D-Glucosaminic Acid & + & G4 & L-Ornithine & + \\
\hline B1 & i-Erythrito & + & D9 & D-Glucuroni Acid & + & G5 & L-Phenylalanine & + \\
\hline B2 & D-Fructose & + & D10 & $\alpha$-Hydroxy Butyric Acid & + & G6 & L-proline & + \\
\hline B3 & L-Fucose & + & D11 & $\beta$-Hydroxy Butyric Acid & + & G7 & L-Pyroglutamic Acid & + \\
\hline B4 & L-Fucose & + & D12 & $\gamma$-Hydroxy Butyric Acid & + & G8 & D-Serine & - \\
\hline B5 & Gentiobiose & + & E1 & p-Hydroxy Phenylacetic Acid & - & G9 & L-Serine & + \\
\hline B6 & $\alpha$-D-Glucose & + & E2 & Itaconic Acid & + & G10 & L-Threonine & + \\
\hline B7 & m-Inositol & + & E3 & $\alpha$-Keto Butyric Acid & + & G11 & D,L-Carnitine & + \\
\hline B8 & $\alpha$-D-Lactose & + & E4 & $\alpha$-Keto Glutaric Acid & + & G12 & $\gamma$-Amino Butyric Acid & - \\
\hline B9 & Lactulose & + & E5 & $\alpha$-Keto Valeric Acid & + & H1 & Urocanic Acid & + \\
\hline $\mathrm{B} 10$ & Maltose & + & E6 & D,L-Lactic Acid & + & $\mathrm{H} 2$ & Inosine & + \\
\hline B11 & D-Mannitol & + & E7 & Malonic Acid & + & $\mathrm{H} 3$ & Uridine & + \\
\hline B12 & D-Mannose & + & E8 & Propionic Acid & + & $\mathrm{H} 4$ & Thymidine & + \\
\hline $\mathrm{C} 1$ & D-Melibiose & + & E9 & Quinic Acid & + & H5 & Phenyethylamine & - \\
\hline $\mathrm{C} 2$ & $\begin{array}{l}\beta \text {-Methyl- } \\
\text { D-Glucoside }\end{array}$ & + & E10 & D-Saccharic Acid & + & H6 & Putrescine & + \\
\hline $\mathrm{C} 3$ & D-Psicose & + & E11 & Sebacic Acid & - & $\mathrm{H} 7$ & 2-Aminoethanol & + \\
\hline $\mathrm{C} 4$ & D-Raffinose & + & E12 & Succinic Acid & + & $\mathrm{H} 8$ & 2,3-Butanediol & + \\
\hline $\mathrm{C} 5$ & L-Rhamnose & + & $\mathrm{F} 1$ & Bromo Succinic Acid & + & $\mathrm{H} 9$ & Glycerol & + \\
\hline C6 & D-Sorbitol & + & $\mathrm{F} 2$ & Succinamic Acid & + & $\mathrm{H} 10$ & $\mathrm{D}, \mathrm{L}-\alpha$-glycerol Phosphate & + \\
\hline $\mathrm{C} 7$ & Sucrose & + & F3 & Glucuronamide & + & H11 & Glucose-1-Phosphate & + \\
\hline $\mathrm{C} 8$ & D-Trehalose & + & $\mathrm{F} 4$ & L-Alaninamide & + & H12 & Glucose-6-Phosphate & + \\
\hline
\end{tabular}

The "+" indicates a positive reaction; “-” indicates a negative reaction;“-/+" indicates a lower

\section{Discussion}

Result from this study indicated that the three isolates YFY 02, HY, 13-1 used as a soil drench or seed treatment had a varying effect in suppressing clubroot under both greenhouse and field conditions. The inhibitory effect depended on bacterial isolate, and bacterial components as well as the bacterial application method. The disease severities of these bacterial isolates were lower than that of the fungicide $1 \%$ phenazino-1-carboxylic acid in Lufeng. Therefore, the results revealed that the three bacterial isolates may have a potential to be developed as a promising commercial biological control agents in the future.

The biocontrol effect of the three isolates against Chinese cabbage clubroot was affected by the inoculation time of both antagonistic bacteria and pathogen. In our experiment, when the three bacterial isolates were 


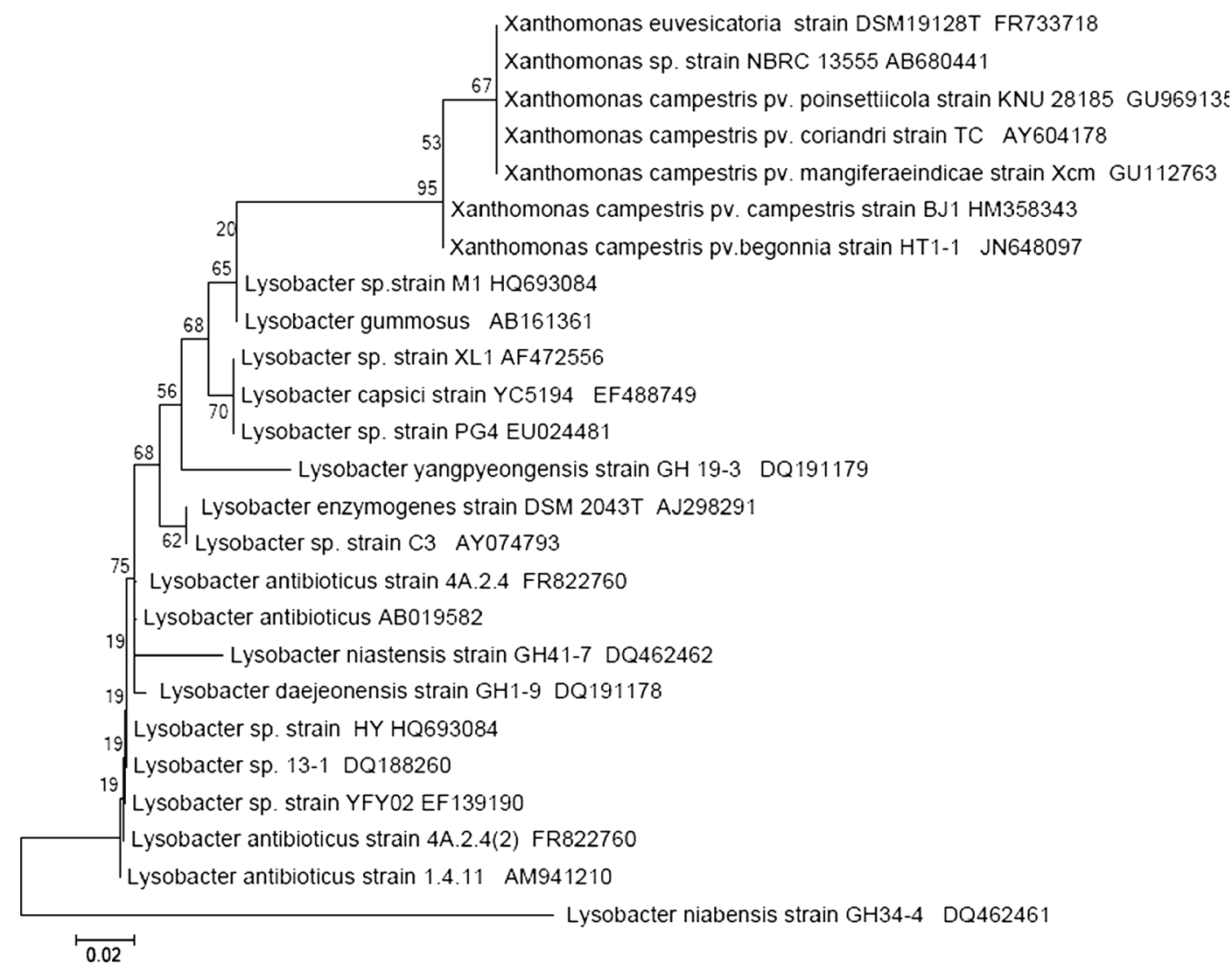

Fig. 1 Phylogenetic tree of the Lysobacter YFY 02, HY and 13-1 on the 16S rDNA gene sequences

applied as a soil drench, bacterial inoculation before pathogen inoculation gave a lower disease severity than both at the same time or with post-pathogen inoculation. This decreased disease severity may be due to these biocontrol isolates establishing in the rhizosphere and occupying the surface of roots or root hairs. However, when the three bacterial isolates were applied as seed treatments, bacterial inoculation before pathogen inoculation caused a higher disease severity than when inoculated at the same time as the pathogen. The contrary effect of inoculation time on disease severity of bacteria used as a soil drench and seed treatment revealed a complex interaction between antagonistic bacteria and the fungal pathogen.

Clubroot severity could be reduced by bacterial isolates used both as a soil drench and seed treatment; however compared to a soil drench application, seed treatments delivered a smaller fraction of the number of living bacteria per seedling, which would be more practical than a soil drench for use in the extensive agricultural system employed for cruciferous crop production. Furthermore, this result also indicated that chitosan applied as seed treatment was able to reduce clubroot severity with better biocontrol efficiency than that suggested by previous published reports (Kurowski et al. 2009). This result is also consistent with the result of Li et al. (2012), who found that chitosan not only inhibits spore germination and clubroot occurrence, but also stimulates the seeding growth of Chinese cabbage.

Three isolates reduced clubroot severity under both greenhouse and field conditions to different degrees compared to the control. Narisawa et al. (2005) reported that control of clubroot on Chinese cabbage using the endophytic fungus Heteroconium chaetospira was more consistently effective when pathogen inoculum was at or below $1 \times 10^{5}$ resting spores per $g$ of soil. In order to improve the efficiency of the biocontrol agents under high disease pressure, it will be necessary to develop an integrated disease management system (Donald et al. 2006). Indeed, better efficiency could be achieved by the combination of biocontrol agents and other control measures, such as a resistant cultivar, crop rotation (Wallenhammar 1996; Cheah et al. 2006), seeding date selection (McDonald and Westerveld 2008), soil 
Table 3 Clubroot disease severity of three Lysobacter isolates applied as a soil drench on Chinese cabbage under greenhouse conditions

\begin{tabular}{llll}
\hline Treatment & Trail 1 $^{\mathrm{a}}$ & Trail 2 $^{\mathrm{b}}$ & Trail 3 $^{\mathrm{c}}$ \\
\hline CK $^{\mathrm{d}}$ & $70.0 \mathrm{a}$ & $74.2 \mathrm{a}$ & $58.9 \mathrm{a}$ \\
YFY 02 & $28.0 \mathrm{c}$ & $34.7 \mathrm{~d}$ & $20.0 \mathrm{~d}$ \\
$\mathrm{HY}$ & $17.8 \mathrm{~d}$ & $34.7 \mathrm{~d}$ & $34.5 \mathrm{bc}$ \\
$13-1$ & $30.0 \mathrm{c}$ & $42.0 \mathrm{c}$ & $36.7 \mathrm{~b}$ \\
$\mathrm{R}^{\mathrm{f}}$ & $34.0 \mathrm{~b}$ & $58.7 \mathrm{~b}$ & $38.0 \mathrm{~b}$ \\
\hline
\end{tabular}

a. The bacterial isolates and fungicide were applied prior to the pathogen inoculum.

b. Applying the resting spores of the pathogen and bacterial isolates at the same time.

c. Applying the resting spores of the pathogen before the bacterial isolates and fungicide were applied.

d. Plants were inoculated with $50 \mathrm{ml}$ of different bacterial CFC described as above while the $\mathrm{CK}$ was treated with sterile water of the same volume. The resting spore of Plasmodiophora brassicae was inoculated by soil-drenching in all treatments as described.

e. Means followed by the same letter within a column are not significantly different as determined by the LSD test $(p=0.05)$. The data were expressed as the average of three replications and three repetitions.

f. The "R" means "phenazino-1-carboxylic acid".

Table 4 Clubroot disease severity of three Lysobacter isolates applied as a seed treatment on Chinese cabbage grown under greenhouse conditions

\begin{tabular}{lll}
\hline Treatment & ${\text { Trial } 1^{\mathrm{a}}}^{\mathrm{a}}$ & Trial 2 \\
\hline $\mathrm{CK}^{\mathrm{c}}$ & $100.0 \mathrm{a}$ & $93.0 \mathrm{a}$ \\
YFY 02 & $61.9 \mathrm{c}$ & $68.1 \mathrm{~b}$ \\
$\mathrm{HY}$ & $66.7 \mathrm{c}$ & $62.6 \mathrm{c}$ \\
$13-1$ & $54.7 \mathrm{~d}$ & $54.3 \mathrm{~d}$ \\
$\mathrm{R}^{\mathrm{e}}$ & $72.6 \mathrm{~b}$ & $69.0 \mathrm{~b}$ \\
Chitosan & $35.7 \mathrm{e}$ & $47.0 \mathrm{e}$ \\
\hline
\end{tabular}

a. The bacterial isolates and fungicide were applied prior to the pathogen inoculum.

b. Applying the resting spores of the pathogen and bacterial isolates at the same time.

c. Plants were inoculated with $50 \mathrm{ml}$ of different bacterial CFC described as above while the $\mathrm{CK}$ was treated with sterile water of the same volume. The resting spore of Plasmodiophora brassicae was inoculated by soil-drenching in all treatments as described.

d. Means followed by the same letter within a column are not significantly different as determined by the LSD test $(p=0.05)$. The data were expressed as the average of three replications and three repetitions.

e. The "R" means " phenazino-1-carboxylic acid".
Table 5 Clubroot disease severity three Lysobacter isolates on Chinese cabbage in two fields experiments

\begin{tabular}{lll}
\hline Treatment & Tonghai & Lufeng \\
\hline $\mathrm{CK}^{\mathrm{a}}$ & $70.0 \mathrm{a}^{\mathrm{b}}$ & $43.6 \mathrm{a}$ \\
YFY 02 & $26.0 \mathrm{e}$ & $23.1 \mathrm{c}$ \\
$\mathrm{HY}$ & $34.0 \mathrm{~d}$ & $20.5 \mathrm{~d}$ \\
$13-1$ & $45.0 \mathrm{c}$ & $23.0 \mathrm{c}$ \\
$\mathrm{R}^{\mathrm{c}}$ & $64.0 \mathrm{~b}$ & $26.0 \mathrm{~b}$ \\
cyazofamid & $33.0 \mathrm{~d}$ & $5.5 \mathrm{e}$ \\
\hline
\end{tabular}

a. ${ }^{\text {a }}$ Means followed by the same letter within a column are not significantly different as determined by the LSD test $(p=0.05)$. The data were expressed as the average of three replications and three repetitions.

b. Plants were inoculated with $100 \mathrm{ml}$ of different bacterial CFC described as above while the CK was treated with sterile water of the same volume. The resting spore of Plasmodiophora brassicae was inoculated by soil-drenching in all treatments as described.

c. The "R" means " phenazino-1-carboxylic acid"

amendment (Webster and Dixon 1991a, b; Dixon and Page 1998), chemical control (Suzuki et al. 1995; Takeshi et al. 2004), and other biological control measures (Narisawa et al. 1998; Cheah et al. 2006). Therefore, further studies should be performed to examine the combined effect of the three bacterial isolates and other measures under high disease pressure.

The mechanisms that underlie the activities of these biocontrol agents for clubroot control hves not been determined, but antibiosis is a likely candidate. Indeed, in this study, the CFC of Lysobacter spp. reduced clubroot severity on Chinese cabbage under both greenhouse and field conditions. Furthermore, Li et al. (2008) isolated a heat-stable antifungal factor (HSAF) from $L$. enzymogenes strain $\mathrm{C} 3$, which was an antibiotic complex consisting of dihydro-maltophilin and structurally related macrocyclic lactams and was found to be responsible for the antagonism of strain $\mathrm{C} 3$ against fungi and oomycetes.

Li et al. (2012) identified chitosanase and PBR1 protein as well as the antibiotics macrolactin, diffcidin, and cyclic lipopeptides such as fengycin, in strain XF-1 of $B$. subtillus. These CFC not only strongly inhibited the germination of resting spores, but also provided a biocontrol efficacy of clubroot on Chinese cabbage. Therefore, these active components may be related to clubroot biocontrol. Interestingly, the key active compounds have been extracted from culture supernatants of three Lysobacter isolates with excess acetate and 
concentrated in vacuum, and then thin-layer chromatography with silica gel plate from fractions, and finally analyzed as 1,6-Dimethoxy phenazine and butyl phthalates by Gas-Chromatography-MS spectrometer, while both the key active compounds all inhibit the germination of resting spores (Lanfang et al. 2014; Folman et al. 2004). Although it is still not clear whether these bacterial agents are able to penetrate roots of crucifer plants and stimulate them against clubroot as reported with other endophytes (Morita et al. 2003), this result suggests that antimicrobial metabolites may play a role in suppression of antagonistic bacteria against clubroot. The modes of action of the antagonistic bacteria under in vivo conditions are being further investigated, and a better understanding of them will provide useful information for designing the efficiency of product delivery strategies against clubroot.

However, in the Tonghai county field trial, the control efficacy was inconsistent with that of the Lufeng trial. The two field treatments of three Lysobacter isolates in the Lufeng trial were substantially more effective than in the Tonghai trail.

Acknowledgment This study is supported financially by the Special Fund for Agro-scientific Research in the Public Interest China Ministry of Agriculture $(201003029,201303015)$ and National Natural Science Foundation in China(31360002).

Open Access This article is distributed under the terms of the Creative Commons Attribution License which permits any use, distribution, and reproduction in any medium, provided the original author(s) and the source are credited.

\section{References}

Arie T, Kobayashi Y, Kono Y et al (1999) Control of clubroot of crucifers by Phoma glomerata and its product epoxydon. Pesticide Science 55:602-604

Cheah LH, Veerakone S, Kent G (2000) Biological control of clubroot on cauliflower with Trichoderma and Streptomyces spp. New Zealand Plant Protection 53:18-21

Cheah LH, Gowers S, Marsh AT (2006) Clubroot control using Brassica break crops. Acta Horticulturae 706:329-332

Christensen P, Cook D (1978) Lysobacter, a new genus of nonfruiting, gliding bacteria with a high base ratio (soil and water organisms). International Journal of Systematic Bacteriology 28: 367-393

Dixon GR, Page LV (1998) Calcium and nitrogen eliciting alterations to growth and reproduction of Plasmodiophora brassicae (clubroot). Acta Horticulturae 459:343-349

Donald EC, Porter IJ, Lancaster RA (2002) Strategic application of lime, fertilisers and fungicides for improved control of clubroot. Cruciferae Newsletter 24:81-82
Donald EC, Porter IJ, Faggian R et al (2006) An integrated approach to the control of clubroot in vegetable Brassica crops. Acta Horticulturae 706:283-300

Feng L, Lihui Z, Ji G (2013) Identification the clubroot of cruciferous vegetables race in Yunnan and Tibet. Chinese Vegetables 20:77-81 (in Chinese)

Folman LB, Postma J, Van Veen JA (2003) Characterization of Lysobacter enzymogenes (Christensen and Cook, 1978) strain $3.1 \mathrm{~T} 8$, a powerful antagonist of fungal disease of cucumber. Microbiology Research 158:107-115

Folman LB, De K, Postma J et al (2004) Production of antifungal compounds by Lysobacter enzymogenes isolate $3.1 \mathrm{~T} 8$ under different conditions in relation to its efficacy as a biocontrol agent of Pythium aphanidermatum in cucumber. Biological Control 31:145-154

Haiyan, Xu., (2011). The study of Yunnan canola resistant varieties clubroot screening and control techniques. Master's thesis of Chinese Academy of Agricultural Sciences

Howard RJ, Strelkov SE, Harding MW (2010) Clubroot of cruciferous crops-new perspectives on an old disease. Canadian Journal of Plant Pathology 32(1):43-57

Huang Y (2010) Biological Control of Plant Diseases. Science Press, Beijing (in Chinese)

Islam MT, Hashidoko Y, Deora A et al (2005) Suppression of damping-off disease in host plants by rhizoplane bacterium Lysobacter sp. strain SB-K88 is linked to plant colonization and antibiosis against soilborne penosporomycetes. Applied Environmental Microbiology 71:3786-3796

Jaschke D, Dugassa-Gobena D, Karlovsky P, Vidal S, LudwigMuller J (2010) Suppression of clubroot (Plasmodiophora brassicae) development in Arabidopsis thaliana by the endophytic fungus Acremonium alternatum. Plant Pathology 59: 100-111

Joo, G. J., Kim, Y. M., Kim, J. W., et al. (2004). Biocontrol of cabbage clubroot by the organic fertilizer using Streptomyces sp. AC-3. Korean Journal of Microbiology and Biotechnology, 32, 172178.

Kim S, Shin C, Moon S et al (2004) Isolation and characterization of Streptomyces spKACC91027 against Plasmodiophora brassicae

Kinsella K, Schulthess CP, Morris TF, Stuart JD (2009) Rapid quantification of Bacillus subtilis antibiotics in the rhizosphere. Soil Biology and Biochemistry 41:374-379

Kurowski TP, Majchrzak B, Kowalska E (2009) The effectiveness of the biological control of clubroot(Plasmodiophora brassicae) in brassicaceae plants. Phytopathologia 52:512

Lanfang, Wei., Lihong, Zhou., Guanghai, Ji., et al. (2014) Identification the antimicrobial substances of Lysobacter antibioticus 13-1 and evaluation of rice bacterial blight control effect. Microbiology ( in Chinese).

Lee SO, Choi GJ, Choi YH et al (2008) Isolation and characterization of endophytic actinomycetes from Chinese cabbage roots as antagonists to Plasmodiophora brassicae. Journal of Microbiology Biotechnology 18(11):1741-1746

Li, B., Shi, Y., Zhou, Q., et al. (2012). Effect of chitosan on seed germation, seedling growth and the clubroot control in Chinese cabbage. journal of food agriculture \& environment, 10, 101-105.

Lihong, Zhou and Guanghai, Ji.( 2013). First report of bacterial leaf spot of rieger begonia caused by Xanthomonas campestris pv. begoniae in China. Plant Disease, 97(2), 282. 
Li S, Jochum CC, Yu F et al (2008) An antibiotic complex from Lysobacter enzymogenes strain C3: Antimicrobial activity and role in plant disease control. Phytopathology 98:695-701

Li, X., Wang, Y., Wu, Y., et al. (2012), ESI LC-MS and MS/MS characterization of antifungal cyclic lipopeptides produced by Bacillus subtilis XF-1. Journal of Molecular Microbiology and Biotechnology, 22(2), 1 76-185

McDonald MR, Westerveld SM (2008) Temperature prior to harvest influences the incidence and severity of clubroot on two Asian brassica vegetables. Hort Science 43:1509-1513

Morita S, Azuma M, Aoba T et al (2003) Induced systemic resistance of Chinese cabbage to bacterial leaf spot and Alternaria leaf spot by the root endophytic fungus, Heteroconium chaetospira. Journal of General Plant Pathology 69:71-75

Narisawa K, Tokumasu S, Hashiba T (1998) Suppression of clubroot formation in Chinese cabbage by the root endophytic fungus, Heteroconium chaetospira. Plant Pathology 47:206-210

Narisawa K, Shimura M, Usuki F et al (2005) Effects of pathogen density, soil moisture, and soil $\mathrm{pH}$ on biological control of clubroot in Chinese cabbage by Heteroconium chaetospira. Plant Disease 89:285-290

Peng G, Gossen BD, Strelkov SE et al (2009) Effect of selected biofungicides for control of clubroot on canola. Canadian Journal of Plant Pathology 31:145-146

Peng G, Hwang SF, McDonald MR et al (2010) Control of clubroot (Plasmodiophora brassicae) with microbial and synthetic fungicides. Phytopathology 100:99

Puopolo G, Raio A, Zoina A (2010) Identification and characterization of Lysobacter capsici strain PG4: a new plant healthpromoting rhizo bacteriaium. Journal of Plant Pathology 92(1):157-164

Romanenko LA, Uchino M, Tanaka N et al (2008) Lysobacter spongiicola $\mathrm{sp}$. Nov Isolated from anaerobic granules in an upfow anaerobic sludge blanket rector International Journal of Systematic and Evolutionary Microbiology 55(3):1155-1161

Suzuki K, Sugimoto K, Hayashi H et al (1995) Biological mode of action of fluazinam, a new fungicide for Chinese cabbage clubroot. Annals of the Phytopathological Society of Japan 61:395-398

Sullivan RF, Holtman MA, Zylstra GJ et al (2003) Taxonomic positioning of two biological control agents for plant diseases as Lysobacter enzymogenes based on phylogenetic analysis of $16 \mathrm{~S}$ rDNA, fatty acid composition and phenotypic characteristics. Journal of Applied Microbiology 94(6): $1079-1086$

Takeshi O, Terumasa K, Shigeru M et al (2004) Development of a novel fungicide, cyazofamid. Journal of Pesticide Science 291: 147-152

Usuki F, Narisawa K (2007) A mutualistic symbiosis between a dark septate endophytic fungus, Heteroconium chaetospira, and a non-mycorrhizal plant, Chinese cabbage. Mycologia 99:175-184

Wallenhammar AC (1996) Prevalence of Plasmodiophora brassicae in a spring oilseed rape growing area in central Sweden and factors influencing soil infestation levels. Plant Pathology 45:710-719

Wang J, Huang Y, Yao J et al (2011) Identification and control effects of two antagonistic actinomycetes against clubroot. Scientia Agricultural Sinica 44(13):2692-2700 (in Chinese)

Webster MA, Dixon GR (1991a) Boron pH and inoculum concentration influencing colonization by Plasmodiophora brassicae. Mycological Research 95:74-79

Webster MA, Dixon GR (1991b) Calcium, pH and inoculum concentration influencing colonization by Plasmodiophora brassicae. Mycological Research 95:64-73

Yang J, Kloepper JW, Ryu CM (2009) Rhizosphere bacteria help plants tolerate abiotic stress. Trends in Plant Science 14:1-4

Yong L, Xiaoqing H, Shaoying, K et al (2009) Evaluation of resistance of rapeseed varieties to club root infected by Plasmodiophora brassicae in Sichuan. Chinese Journal of Oil Crop Sciences. 31(1):90-93 (In Chinese)

Yuen GY, Zhang Z (2001) Control of brown patch disease using the bacterium Stenotrophomonas maltophilia strain C3 and culture fluid. International Turf grass Society Research Journal 9:742-747

Yueqiu H, Guoru X, Chengming F (2008) Biological agents and application against crucifer clubroot. China 9-12 (In Chinese)

Zhang Z, Yuen GY (1999) Biological control of Bipolaris sorokiniana on tall fescue by Stenotrophomonas maltophilia C3. Phytopathology 89:817-822

Zhongda F (1998) Methods of Plant Pathology. China Agriculture Press, Beijing 